\title{
PENETRATING SCREWDRIVER WOUND TO THE HEAD
}

\author{
Patricia Bozzeto-Ambrosi', Leonardo Ferraz Costa ${ }^{1}$, Hildo Azevedo-Filho ${ }^{2}$
}

Penetrating screwdriver wounds to the head (PSWH) are very unusual in neurosurgical practice and are rarely described in the literature. A screwdriver being a tool is rarely used as a weapon. The majority of cases are extracted from medical legal situations or are found among psychiatric patients. However, screwdrivers, because of their rigid structure and narrow tip, may forcefully penetrate the cranial bone and cause severe injuries within the brain substance or to the vascular bed.

Intracranial injuries due to PSWH without causing functional deficits as in the present case have not yet been reported in the literature.

\section{CASE}

A 30-year-old man presented to our emergency department after an assault with a screwdriver sticking out of the head. He was brought by ambulance and paramedical group. On admission, he was conscious with Glasgow Coma Score (GCS) 15, although he demonstrated disproportioned right hemiparesis and ideational apraxia. The physical examination revealed the screwdriver lodged in the left parietal region (Fig 1A). An initial plain skull radiograph showed the trajectory of the penetrating wound (Figs 1B, 1C). Axial computerized tomography (CT) scan images showed that the screwdriver had crossed the left hemi- sphere and reached the frontal region (Figs 2A, 2B). The patient was then taken to the operative room in order to the remove the foreign body. Under general anesthesia and on prone position, a small craniectomy was carried surrounding the inflicting object which was pulled out without overdue traction followed by rigorous hemostasis and generous irrigation. The duramater was sutured in a watertight fashion with prolene 4.0 and a small duroplasty was performed with authologous pericranium. His neurological impairment recovered completely in two days and he received endovenous antibiotics for ten days. He was then discharged without any physical sequelae (Fig 3A). On the seventh post-operative day, he had a CT scan done which showed a small hematoma of less than two centimeters in the left middle frontal gyrus, without surrounding edema or signs of mass effect, which was managed conservatively (Fig 3B).

The patient authorized the authors the utilization of these records by informed consent.

\section{DISCUSSION}

The group of wounds caused by knives, nails, spikes, forks, scissors, screwdrivers and other assorted objects represents a smaller fraction of $\mathrm{PWH}^{\prime}$. Unusual PWH, most commonly, occur in the thin bones of the skull, especially in the orbital surfaces and the squamous portion of the
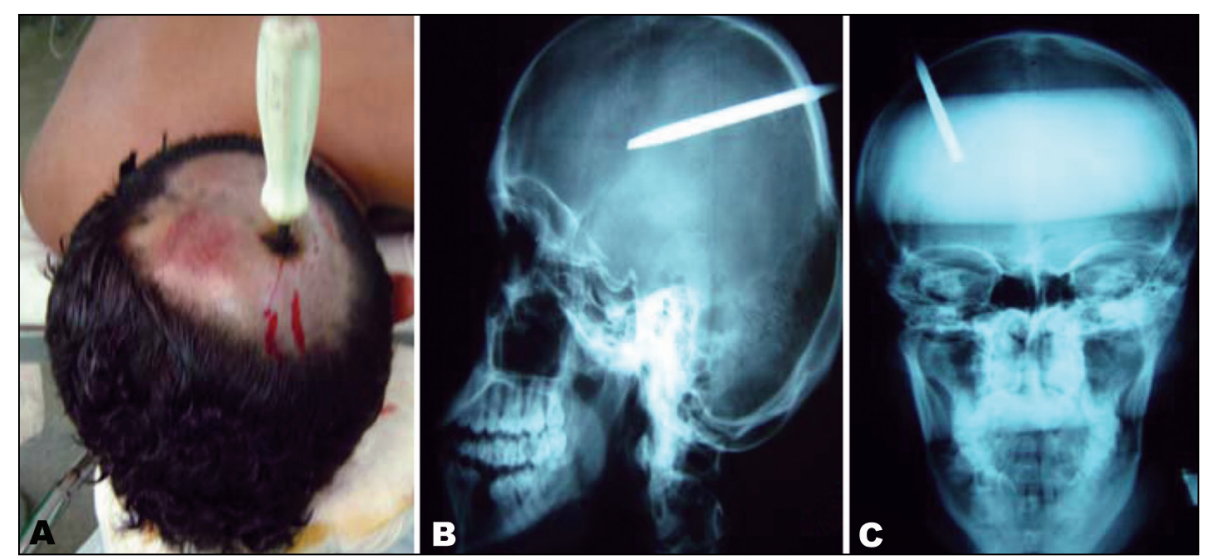

Fig $7 A, 7 B, 1 C$. The screwdriver lodged in the left parietal region. Images of plain skull $x$-rays showing the trajectory of the penetrating agent.

\section{FERIMENTO PENETRANTE DE CRÂNIO POR CHAVE DE FENDA}

Chair of Neurological Surgery; Hospital da Restauração, University of Pernambuco, Recife PE, Brazil: 'Neurosurgery Resident; ${ }^{2}$ Professor of Neurological Surgery.

Received 8 June 2007, received in final form 19 October 2007. Accepted 23 November 2007.

Dr. Hildo Azevedo-Filho - Rua Apipucos 317 / 601 -52071-000 Recife PE - Brasil.E-mail: azevedoh@uol.com.br, patri_boz@yahoo.fr 


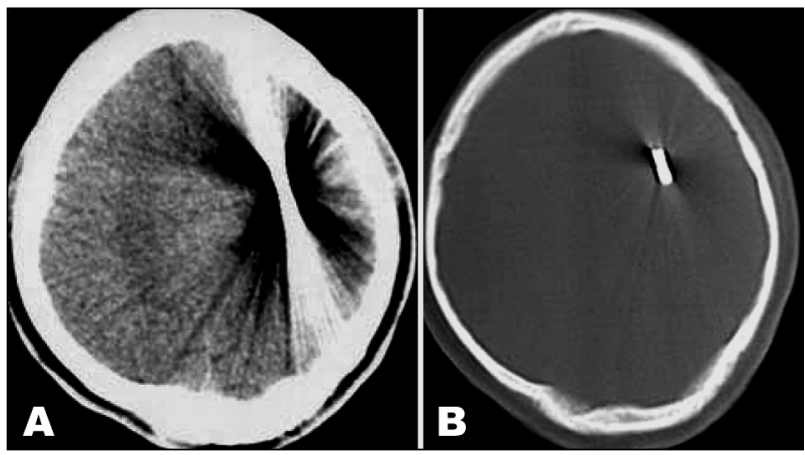

Fig 2A, 2B. CT scan images showing that the screwdriver had partially crossed the left hemisphere and reached the frontal region

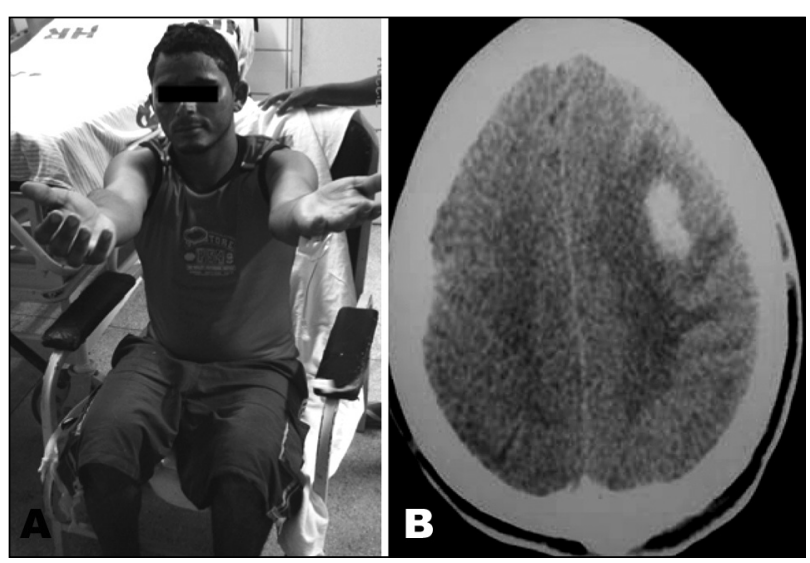

Fig 3A, 3B. Photography to discharge status of patient. Post-operative CT scan image showing a remaining small hematoma in middle frontal gyrus.

temporal'. They remain a frequent cause of neurosurgical admissions to emergency units in South Africa ${ }^{2}$.

Medical reports of bizarre stab wounds to the brain date from as early as $1806^{3,4}$. One of those first cases regarding PWH was reported in 1848. Phineas Gage was a foreman of a railway construction and victim of accidental explosion. He had a piece of iron blown into his head. $\mathrm{He}$ is probably the most famous patient to have survived such a severe damage to the brain in the nineteenth century and for sure he is also the first patient from whom we soundly learned about the relationship between cerebral functions and brain structural lesions ${ }^{3-5}$.

In a large study on unusual PWH, Nathoo et al. analyzed 597 patients in 12-year period and the results revealed outcome predictors that are strikingly similar to other forms of open and closed neurotrauma. The GCS score was the most significant predictor of outcome in low-velocity PWH. As the cases of brainstem lesions had a great propensity for vascular damage, survivors were left incapacitated by severe and fixed neurological deficits ${ }^{2}$.

The mechanisms of neuronal and vascular injury caused by cranial stab wounds may differ from those caused by other types of head trauma. Unlike missile injuries, no concentric zone of coagulative necrosis caused by dissipated energy is present. Unlike motor vehicle accidents, no diffuse shearing injury to the brain occurs. Unless an associated hematoma or infarct is present, cerebral damage caused by stabbing is largely restricted to the wound tract. A narrow elongated defect, or so-called slot fracture, sometimes is produced by a stab wound and is diagnostic when identified.

However, in some cases in which skull penetration is proven, no radiological abnormality can be identified. In a series of stab wounds, de Villiers, in South Africa, reported a mortality of $17 \%$, mostly related to vascular injury and massive intracerebral hematomas. Stab wounds to the temporal fossa are more likely to produce major neurological deficits, because of the thinness of the temporal squama and the shorter distance to the brain stem and important vascular structures. Patients in whom the penetrating object is left in place have a significantly lower mortality than those in whom the objects are inserted and then removed ( $26 \%$ versus $11 \%$ respectively) ${ }^{6}$.

Regarding PWH, in 1995, SmrKolj et al. described two patients with unusual intracranial foreign bodies. In one, it was a homicide and in the other, it resulted from a selfinflicted injury ${ }^{7}$. Both patients died, 5 and 14 days respectively, after removal of the lesion producing agent. In both cases death was due to brain ischemia and the resulting edema secondary to arterial injury?

Tutton et al. also reported four patients with PSWH. Two cases were fatal and the others were left with functional deficits. In two patients, a penetrating injury was not suspected, initially, because the history was limited and the significance of the small entry wounds was not appreciated. They emphasized that any cranial wound should be carefully examined because a penetrating injury could be easily overlooked ${ }^{8}$.

Regarding reports in the Brazilian literature, Yamashita et al. reported PWH caused by suicide attempt with the introducing of two nails in the head. The patient was submitted to bifrontoparietal craniotomy without mobilizing the superior sagital sinus and when discharged he was considered to be a good outcome?

More recently, Andrade et al. reported a case of PSWH to the brainstem with good outcome and unusual clinical presentation $^{10}$.

It is fundamental to stress that in patients where there is the possibility of an intracranial penetrating wound, skull X-rays and subsequent CT scan and possibly cerebral angiography should be requested. As compound wounds, these injuries require appropriate antibiotic cover and tet- 
anus prophylaxis. Further neurosurgical assessment will determine whether formal debridement, removal of haematoma together with devitalized tissue and depressed bony fragments will be deemed to be necessary ${ }^{8}$.

Therefore, the rationale for successful treatment of PWH is fundamentally based on the removal of clots and devitalized tissues, prevention of infection and late epilepsy. Operative delay greater than 48 hours from the time of injury dramatically increases the incidence of infection from 4.6 to $36.5 \% \%^{11,12}$.

Finally, the important lesson we could learn from this case was that precocious treatment, careful and meticulous handling of the inflicting agent and the brain wound, preferably under magnification, together with effective amount of post-operative antibiotics are the most important measures to promote recovery of the patient with the less possible neurological impairment.

Ultimately, improvements in socioeconomic standards, in conjunction with integration of preventive measures through education and community mobilization, are necessary to reduce this form of penetrating neurotrauma.

\section{REFERENCES}

1. Harrington T, Apostolides P. Penetrating brain injury. In Cooper PR, Golfinos JG (Eds). Head injury. Ed 4. New York: McGraw-Hill 2000: 349-360.

2. Nathoo N, Boodhoo H, Nadvi SS, Naidoo SR, Gouws E . Transcranial brainstem stab injuries: a retrospective analysis of 17 patients. Neurosurgery 2000;47:1117-1123.

3. Mason F. Case of a young man who had a pitchfork driven into his head four inches who speedily got well. Lancet 1870;1:700-701.

4. Barker FG. Phineas among the phrenologists: the American crowbar case and nineteenth-century theories of cerebral localization. J Neurosurg 1995;82:672-682.

5. MacMillan M. Commemorating the $150^{\text {th }}$ anniversary of Phineas Gages's accident. J Hist Neurosci 2000;9:90-93.

6. De Villiers J, Sevel D. Intracranial complications of transorbital stab wounds. Br J Ophthalmol 1975;59:52-56.

7. Smrkolj V, Balazic J, Princic J. Intracranial injuries by a screwdriver. Forensic Sci Int 1995;29:211-216.

8. Tutton MG, Chitnavis B, Stell IM. Screwdriver assaults and intracranial injuries. J Accid Emerg Méd 2000;17:225-226.

9. Yamashita M, Abrahão N Jr, Lamachia C. Tentativa de suicídio pela introdução de dois pregos na cabeça. Arq Neuropsiquiatr 1998;56: 317-319.

10. Andrade AF, Almeida AN, Muoio VM, Marino R Jr. Penetrating screwdriver injury to the brainstem: case illustration. J Neurosurg 2006;104:853.

11. Bullock RM, Chesnut R, Ghajar J, et al. Surgical management of depressed cranial fractures. Neurosurgery 2006;58(Suppl):S56-S58.

12. Wylen EL, Willis BK, Nanda A. Infection rate with replacement of bone fragment in compound depressed skull fractures. Neurosurgery 2006;58(Suppl):S56-S58 